\section{Judgments of verticality as a function of exposure duration, luminance, frame tilt, and frame-rod interval*}

\author{
HENRY A. CROSS + \\ Colorado State University, Fort Collins, Colo. 80521 \\ JOHN R. SCHUCK \\ Bowling Green State University, Bowling Green, Ohio 43402 \\ and \\ EUGENE DANNEMILLER \\ Wittenberg University, Springfield, Ohio 45501
}

College Ss were selected as field dependent or independent and then given a "signal-detection" version of the rod-and-frame test. Receiver operating characteristic (ROC) curves were calculated for each S's performance under three exposure durations, two luminance levels, and two frame tilts. Like children in a previous study, some Ss responded independently when the frame was tilted $28 \mathrm{deg}$ but dependently at $8 \mathrm{deg}$. Analysis resulted in significance for all main effects and for interactions of dependency classification with duration, with tilt, and with tilt and luminance. Experiment 2 checked the possibility that Ss who were classified differently were differentially sensitive to the perception of verticality, quite apart from the field. Experiment 3 manipulated the interval between frame offset and rod onset. Results show that dependents were profoundly influenced by the frame, even $2,500 \mathrm{msec}$ after its termination.

Schuck, Cross, \& Mills (1970) used a contemporary psychophysical version of the Witkin (Witkin, Dyk, Faterson, Goodenough, \& Karp, 1962) rod-and-frame test (RFT) to study field dependence in a group of children from 8 to 11 years old. On any one trial, the rod was presented in a fixed position either vertical or not vertical within a frame that was tilted either 8 or 28 deg. Electroluminescent tape provided the luminous rod and frame in an otherwise darkened room. The $S$ responded on a rating scale representing his confidence that the rod was vertical. A hit was defined as $\mathrm{S}$ reporting the rod to be vertical when it actually was. A false alarm was defined as $S$ reporting the rod to be vertical when it was actually tilted.

Receiver operating characteristic (ROC) curves were constructed for each $S$ by plotting his proportion of hits (HR) against his proportion of false alarms (FAR). Figure 1 shows ROC curves for two hypothetical Ss plotted from four-cateogry rating data. In this illustration, the two Ss were equally adept at discriminating the vertical from the tilted position of the rod, since their ROC functions are equally deviant from the positive diagonal representing chance

* These data were collected as part of an NSF grant, No. GY -3845 , awarded to Henry A. Cross when he was at Wittenberg University. The writers thank Phillip $K$. Duncan and Kathy A. West, who collected the data reported in Experiment 2.

tPresent address: Department of Psychology, Colorado State University, Fort Collins, Colo. 80521 . performance. The $S$ with the function below the chance diagonal should be labeled "dependent," however, since he tends to call the rod vertical whenever it is tilted like the frame. His area score is .14, which is the area in the unit square under his ROC function. The function lying above the chance diagonal has an area measure of .86 and represents the performance of an independent who is relatively accurate in reporting the vertical positions as vertical.

The ROC area measure correlated highly $(.65$ to .82$)$ with more traditional measures of field dependence, and there was good agreement between Witkin's RFT and the ROC technique for classifying Ss. Several children, however, performed like dependents when the frame was tilted 8 deg but like independents when the frame was tilted $28 \mathrm{deg}$. These children were called "others."

The purpose of Experiment 1 was to study the performance of college Ss on the RFT using the modified ROC procedure. One goal was to find out if some young adults also fit the "others" category. Another was to manipulate the exposure duration and luminance of the rod and frame to discover what effects these variables have upon the performance of independents, dependents, and possible "others."

The Witkin procedure involves relatively long periods of exposure to the tilted rod and frame, since the rod is moved in discrete steps until $S$ judges it to be vertical. The modified approach avoids this difficulty and provides for control over duration and brightness. In the present experiment, Witkin's RFT and the Hidden Figures Test ( $\mathrm{Cf} \cdot 1$, Educational Testing Service) were initially used to select 18 Ss. The modified procedure was then used to observe Ss intensively under different luminance, exposure duration, and frame tilts. The exposures were selected to span the latency of reflexive eye movements. The luminances were chosen so that the rod and frame retained definite contour at the lower level but gave no extraneous spatial cues at the upper level.

\section{EXPERIMENT 1}

Method

A total of 182 students from two introductory psychology classes at Wittenberg University were given screening tests consisting of 12 trials of Witkin's RFT or Witkin's test plus the Cf-1. From this screening, $18 \mathrm{Ss}$ were selected for intensive study. Nine of these had extreme field-dependent scores, i.e., high absolute error on the Witkin RFT and low scores on Cf-1. The other 9 had reverse test scores. Fourteen of the Ss were female.

The rod and frame employed in the experimental phase has been described elsewhere (Schuck, Cross, \& Mills, 1970). It was a large, modified Witkin-type apparatus with frame dimensions of $40 \times 40 \times 1$ in. The rod was $36 \times 1$ in. The rod and frame were made of white electroluminescent tape light (Sylvania Co.). Duration was controlled by a Hunter timer and luminance by variations in the input voltage. The experimental room was totally dark.

The procedure for this phase was essentially that employed by Schuck, Cross, \& Mills (1970). Each S was led into the dark room and was seated

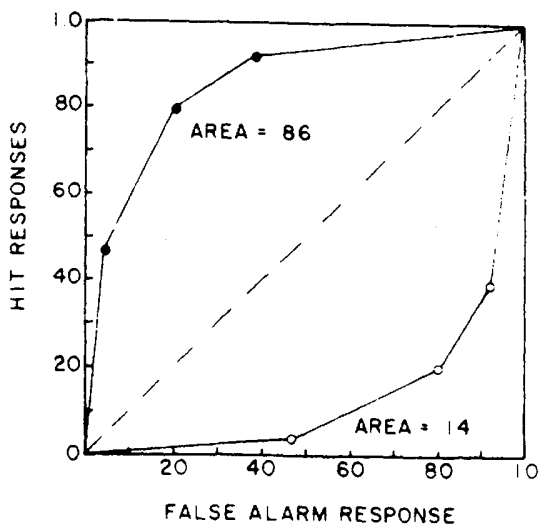

Fig. 1. Two hypothetical ROC functions representing independent (filled circles) and dependent (open circles) performance in the modified rod-and-frame test. The dashed line represents chance performance. 
behind a large screen $10 \mathrm{ft}$ from the rod and frame. He was told that on each trial, he would be asked to open an aperature in the screen before him and that he would then be given a brief presentation of a rod and frame. The $\mathbf{S}$ was told that on half of the trials the rod would be vertical while on the other half it would be tilted. The $S$ was instructed to say, "Yes-sure," or "Yes-not sure," depending upon his certainty, on trials judged to be vertical. On trials judged not to be vertical, $S$ was to respond with either "No-not sure" or "No-sure."

Each paid $S$ was given 96 trials a day for 13 days. The 96 daily trials involved eight trials, four vertical and four not vertical, in each of 12 conditions which were factorial combinations of three durations, 10 , 100 , and $1,000 \mathrm{msec}$, two luminance levels, .03 and $.30 \mathrm{fL}$, and two frame tilts, 8 and $28 \mathrm{deg}$. Over the 13-day testing period, $S$ received 52 vertical and 52 nonvertical trials for each of the conditions. Half of the trials had the frame tilted to S's right and half to his left. On the nonvertical trials, the rod was always tilted $4 \frac{1}{2} \mathrm{deg}$ in the same direction as the frame.

Results and Discussion

Two data points were calculated for each S's yes-no responses, ignoring his confidence ratings. One data point represented S's performance for the duration of $1,000 \mathrm{msec}, .03 \mathrm{fL}$, and 8-deg tilt. The other represented the same duration and luminance but a tilt of $28 \mathrm{deg}$. These conditions were selected as being most similar to those used by Schuck, Cross, \& Mills (1970) to identify Ss by ROC analysis. These ROC classification categories were then incorporated as the between-S factor in a split-plot analysis of variance in which the dependent variable was obtained by measuring the area under each S's ROC function for each condition. The ROC functions were constructed from the rating data according to the procedure described by Green \& Swets (1966). In the resulting analysis, all main effects were significant $(\alpha=.001)$ : luminance $(\mathrm{F}=11.19, \quad \mathrm{df}=1 / 15)$, duration $(\mathrm{F}=15.66, \mathrm{df}=2 / 30)$, dependency classification $(\mathrm{F}=21.56, \mathrm{df}=2 / 15)$, and frame tilt $(\mathrm{F}=100.39, \mathrm{df}=1 / 15)$. Overall performance was superior under the high-luminance condition, where the mean ROC area was .61 compared to one of .58 under low luminance. The mean ROC areas were $.57, .58$, and .64 for the $10-, 100-$, and 1,000-msec durations, respectively. Scheffé's procedure (Hays, 1963) indicated that the 1,000-msec condition was superior to both the 100- and 10-msec conditions but that the latter did not differ $(\alpha=.05)$.
A significant Dependency by Duration interaction $(F=3.84$, $\mathrm{df}=4 / 30, \quad \mathrm{p}<.025)$ indicated that only the independents and "others" contributed to the superiority of the 1,000 -msec duration. In order of increasing duration, mean ROC areas were $.70, .72$, and .79 for independents and $.50, .50$, and .58 for "others." Performance of the dependents worsened under the long duration, as indicated by mean ROC areas of $.30, .30$, and .26 .

The significant main effect of dependency classification and the significant interaction of dependency classification with frame tilt $(F=8.77$, $\mathrm{df}=2 / 9, \quad \mathrm{p}<.01$ ) were both consequences of the criteria used for classification. They do indicate, however, that Ss remained in the same classification across all conditions. Across all conditions, independents maintained a mean ROC area of .74 , the dependents remained dependent with a mean area of .28 , and the "others" " mean area measure was .53. All three groups performed better when the frame was tilted 28 as compared to $8 \mathrm{deg}$. Independents increased their mean ROC area from .67 to .81 and dependents from .17 to .40 . The greatest increase was contributed by "others," who changed from .31 to .75 . This increase was the source of the significant interaction.

The remaining significant effect, the Dependency by Luminance by Tilt interaction, may be described in this way. For the 8-deg frame setting, "others" and dependents showed little change with increasing luminance (.30 to .31 for "others," .17 to .18 for dependents). Mean ROC area for the independents, however, increased from .65 to .69 . In contrast, independents and dependents changed little across luminance conditions at the 28-deg setting ( .80 to .81 for independents and .40 and .40 for dependents), while the performance of "others" increased from .71 to .78 . Six of those Ss classified as independent according to Witkin's procedure remained independent by our classification, and three of the initial independents were subsequently reclassified as "others"; for those initially classified as dependents, however, the ROC classification procedure resulted in three independents, three "others," and only three dependents.

Our present data reveal young adults who also responded like the "other" children of the previous study. The performance of the college independents, "others," and dependents remained consistent with these classification categories across exposure durations, with no significant differences of any kind between the 10 - and 100-msec conditions. This seems to rule out eye movements as an explanation of the difference among classifications. Conklin, Muir, \& Boersma ${ }^{1}$ found differences in the visual tracking movements of dependents and independents. In the present study, however, these differences were maintained at exposure durations of $100 \mathrm{msec}$ or less where visual tracking movements were not occurring. As for reflexive saccadic movements, they cannot be invoked to explain differences obtained with exposures of only $10 \mathrm{msec}$. No attempt was made to control for retinal afterimages. There is general agreement with the child study, and Ss classified as "others" have also been found-this time from a young adult population. Although the two studies are similar in results, the correspondence between the Witkin procedure and the modified procedure is less compelling than it was with children.

\section{EXPERIMENT 2}

This study was an attempt to determine if $\mathrm{Ss}$ in the classification categories were equally accurate in judging verticality in a situation in which the frame portion of the apparatus was not present. Since the tilted frame is present in the RFT, and was in the two previous studies employing a signal-detection approach, it remains possible that Ss in different classifications differ also in their ability to judge the vertical, even in a situation not involving a distorted field.

\section{Method}

The Ss were eight undergraduate students at Wittenberg University. On the basis of their previous performance in the modified procedure, three of the Ss were operationally classified as independents, three were "others," and two were dependents.

Each $\mathrm{S}$ was given 288 trials in which the rod, with no accompanying frame, was presented for $20 \mathrm{msec}$ in a vertical position under an illumination of $.01 \mathrm{fL}$. Randomly interspersed with the vertical trials were 288 trials in which the rod was slightly tilted either to S's right or left. The total 576 trials were distributed over 6 days in which each of three tilt conditions, i.e., rod tilts of $1 \frac{1}{2}, 3$, and $4 \frac{1}{2} \mathrm{deg}$, was presented for 2 blocks each in 16-trial blocks for a total of 96 daily trials. The blocks were presented in a random order for each $S$, except that all tilt conditions had to appear once before any could be repeated.

\section{RESULTS AND DISCUSSION}

The area under the ROC curve was employed as a measure of S's ability to judge verticality. ROC area scores were computed for each $\mathrm{S}$ for each of the conditions in which the tilted rod was displaced $1 \frac{1 / 2}{2}, 3$, or $4 \frac{1}{2} \mathrm{deg}$. These 
Table 1

\begin{tabular}{|c|c|c|c|c|}
\hline Source & df & SS & MS & $\mathrm{F}$ \\
\hline Classification (A) & 2 & $22,541.49$ & $11,270.75$ & $42.25 \dagger$ \\
\hline$S(A)$ & 14 & $3,734.51$ & 266.75 & - \\
\hline Tilt (B) & 1 & $2,520.09$ & $2,520.09$ & $31.09+$ \\
\hline Interval (C) & 2 & $5,439.59$ & 2.719 .79 & $53.09 \dagger$ \\
\hline$A B$ & 2 & 861.79 & 4.30 .90 & $5.32^{*}$ \\
\hline$A C$ & 4 & $1,272.03$ & 318.01 & $6.21 * *$ \\
\hline $\mathrm{BC}$ & 2 & 796.41 & 398.21 & $8.94 \dagger$ \\
\hline $\mathrm{ABC}$ & 4 & 344.76 & 86.19 & 1.93 \\
\hline$S(A)$ by $B$ & 14 & $1,134.95$ & 81.07 & - \\
\hline$S(A)$ by $C$ & 28 & $1,434.38$ & 51.23 & - \\
\hline$S(A)$ by $B C$ & 28 & $1,247.49$ & 44.55 & - \\
\hline Total & 101 & $41,327.49$ & & \\
\hline
\end{tabular}

$* p<.025, * * p<.005 . \tau p<.001$

scores served as the basic datum in a split-plot analysis of variance, where Ss were nested within one of the classifications. The ROC means were $.89, .82$, and .87 for the field independents, "others," and dependents, respectively. These differences were not significant $(\mathrm{F}=.42, \mathrm{df}=2 / 5)$. The overall means for the $1 \frac{1 / 2-}{2}, 3-$, and $41 / 2$-deg rod tilts were $.71, .91$, and .96 , respectively. These differences were significant $(F=54.92, \quad d f=2 / 10$, $\mathrm{p}<.001$ ), and subsequent tests with the Scheffé procedure (Hays, 1963) indicated that the only mean comparison not significant $(\alpha=.01)$ involved the 3 - and $4 \frac{1}{1} 2$-deg conditions. There was no Classification by Tilt Condition interaction $(\mathrm{F}=.78$, $\mathrm{df}=4 / 10$ ). The rating functions (not shown) were remarkably similar for all classifications and became increasingly so as the vertical trials were interspersed with tilts of greater magnitude. There is, then, no basis for concluding that Ss classified as independent, dependent, and "other" in the modified procedure differed in their basic ability to judge rod verticality when the field or background was removed.

\section{EXPERIMENT 3}

This investigation was directed at observing the differential decay function of the frame influence on judgments of rod verticality for Ss classified as independents, dependents, and "others." Since different Ss showed marked differences in their ability to judge the vertical when rod and frame were simultaneously presented (Experiment 1) but did not differ when the frame was withheld (Experiment 2), the Es decided to observe the influence of the frame upon judgments of rod verticality occurring at different intervals after the frame exposure itself was terminated. The basic procedure involved presentation of the frame, its termination, and the presentation of the rod at varying temporal intervals following the termination of the frame exposure.

Method

Nine Wittenberg students enrolled in an introductory course served as Ss in the initial phase of this study. The Ss had been ROC classified in a preliminary RFT. There were five independent Ss and two each in the dependent and "other" categories. Eight students from Bowling Green State University served as $S s$ in a second phase of this experiment, (described below) from that which was conducted at Wittenberg. These Ss were classified in the same way, with four independent Ss and two $S s$ in each of the other classifications.

On each of 8 days, every Wittenberg $S$ received 128 trials, divided into eight blocks of 16 trials each. The daily blocks were factorial combinations of two frame tilts ( 8 and $28 \mathrm{deg}$ ) and four frame-rod delay periods $(0,500$, 1,000 , and $2,500 \mathrm{msec}$ ). These eight blocks were randomized daily for each S. Within the separate blocks, S received eight vertical trials and eight vertical trials the frame was tilted to the right and on half to the left. On nonvertical trials, the frame was always tilted in the same direction as the rod, which was tilted $4 \frac{1}{2} 2$ deg. On all trials, the line voltage of the rod and frame was set at $32 \mathrm{~V}$, producing a luminance of approximately $.01 \mathrm{fL}$. The duration of the frame was $500 \mathrm{msec}$, followed by a delay interval of from 0 to $2,500 \mathrm{msec}$, as previously

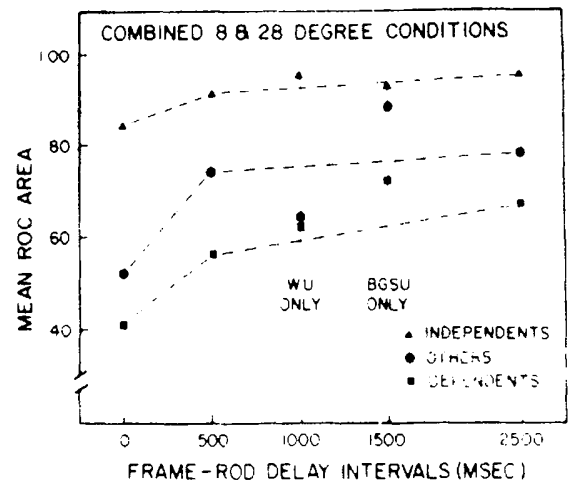

Fig. 2. Mean ROC areas for independents, others, and dependents at different frame-rod delay intervals. which differed in only one particular nonvertical trials. On half of the described, and then by the rod for 500 msec. Each Bowling Green S received the identical procedure, except that the delay interval of 1,000 msec was replaced by an interval of $1,500 \mathrm{msec}$

\section{Results and Discussion}

The rating method was used to calculate ROC functions for each $\mathrm{S}$ under each of the six common conditions. Then the area under each ROC function was calculated as a measure of S's ability to differentiate and correctly label the vertical and tilted rod. Mean area scores were .67 , .78 , and .84 for the $0-, 500-$, and $2,500-\mathrm{msec}$ delays, respectively. The mean for the frame setting of $28 \mathrm{deg}$ was .81 , while that for $8 \mathrm{deg}$ was .72 . Both delay and tilt effects were significant, as shown by the analysis of variance summarized in Table 1 .

When the frame was tilted $8 \mathrm{deg}$, the mean areas were $.58, .75$, and .82 for the 0,500 , and $2,500 \mathrm{msec}$ of delay, respectively. The comparable means for $28 \mathrm{deg}$ of tilt were $.76, .82$, and .87 . Thus, the differences between the two tilt conditions lessened with increasing delays from 0 to $1,000 \mathrm{msec}$, resulting in the significant Tilt by Delay interaction.

Two of the significant $F$ values in Table 1 were the consequence of the procedure used to classify Ss. One was the interaction of dependency classification with frame tilt. The other was the difference between mean area scores of $.90, .68$, and .55 for independents, "others," and dependents, respectively.

Figure 2 illustrates the significant Dependency Classification by Delay interaction. Visual inspection of the figure suggests that the major contribution to this interaction came from the relatively fast improvement in performance of "others" between the $0 \cdot$ and $500-\mathrm{msec}$ delays. The independents improved slowly because they were already performing well. The dependents, on the other hand, performed poorly at the 0 -msec condition and improved only minimally after $500 \mathrm{msec}$. Indeed, one of the striking findings of this study is that, after the frame had been removed $2,500 \mathrm{msec}$, dependents were still performing at a mean level of .68 , which was far below their demonstrated capacity to judge rod verticality (Experiment 2).

\section{REFERENCES}

GREEN D M \& SWETS, J A Signal detection theory and psychophysics. New York: Wiley, 1966.

HAYS, W. L. Statistics for psychologists. New York: Holt, Rinehart \& Winston, 1963.

SCHUCK, J. R.. CROSS, H. A., \& MILLS, D. H. A signal detection analysis of the rod and frame test. Perception 
Psychophysics, 1970, 7, 276-280.

WITKIN, H. A., DYK, R. B., FATERSON, F. 1. Conklin, R. C., Muir, W., \& Boersma,
H. F., GOODENOUGH, D. R. \& KARP, F. J. Field dependency-independency and S. A. Psychological differentiation. New eye movement patterns. Unpublished York: Wiley, 1962 manuscript, 1967.

\title{
Factors affecting the effectiveness of reward power*
}

\author{
SVENN LINDSKOLD \\ Ohio University, Athens, Ohio 45701 \\ and
}

THOMAS V. BONOMA, BARRY R. SCHLENKER, and JAMES T. TEDESCHI State University of New York, Albany, N.Y. 12203

A simulated promisor was given the capability of sending promises and providing rewards to 180 male and female Ss during the course of a mixed-motive conflict interaction. Promises were of either high or low reward value and were fulfilled $10 \%, 50 \%$, or $90 \%$ of the time; the promisor behaved totally, partially, or not at all accommodatively. When the promisor used his power exploitatively, Ss complied more often to promises of high than to promises of low reward values; but when the promisor was totally accommodative, the magnitude of the reward did not affect compliance, suggesting that normative considerations overrode expected value considerations in the latter conditions. Postgame impressions of the promisor were affected by all of the independent variable manipulations.

A contingent promise offers a reward in return for a favor from a target individual. Compliance by the target should be greatest when the value of the promised reward and the probability of receiving the reward are highest. Lindskold \& Tedeschi (1971) conducted a study designed to examine the effects of value and probability associated with promises sent by a simulated source to a $S$ during a mixed-motive interaction. They found a surprisingly high level of target compliance to the promises across all conditions of value magnitudes and probabilities. The negative results were attributed to the fact that the promisor was invariably accommodative on promise-relevant interactions, producing a situation in which the target would benefit even if the promisor did not give the additional offered reward. Lindskold and Tedeschi attributed the results to the fact that the promise signaled predictable cooperation by the source

* The present study was supported in part by Grant No. ACDA-0331 from the U.S. Arms Control and Disarmament Agency (National Research Council) to the second author, by a National Science Foundation fellowship to the third author, and by National Science Foundation Grant GS-27059 to the fourth author. of influence, irrespective of the expected value of the promise, and served to invoke the positive norm of reciprocity that help (cooperation or compliance) should be given for help received (Gouldner, 1960). It follows if this interpretation is correct that the effects of reward magnitude and probability should manifest themselves only when the promisor behaves exploitatively by taking advantage of the target's compliant behavior.

The present experiment employed three levels of promisor accommodativeness when attempting influence $(0 \%, 50 \%$, and $100 \%)$, three levels of promise credibility $(10 \%$, $50 \%$, and $90 \%$ ), two levels of reward magnitude ( 5 and 20 points), and sex of Ss in an attempt to evaluate the relative effects of expected value and accommodativeness on Ss' compliance to promises. A prisoner's dilemma (PD) game was employed to provide a backdrop of social conflict in which the use of inducements would seem justified. It was hypothesized that: (1) magnitude of the promised reward and promise credibility would interact with accommodativeness to determine compliance such that neither variable would affect compliance when the promisor was accommodative, but higher credibility and reward levels would produce more compliance than the lower levels when the source was less than totally accommodative; (2) invariable accommodativeness should, by itself, invoke a norm of reciprocity and gain greater levels of compliance than when the source was partially or invariably exploitative; and (3) females were expected to show a greater degree of cooperativeness throughout the interaction than were males.

SUBJECTS AND APPARATUS

One hundred and eighty Ss, 90 of each sex, partially fulfilled an introductory psychology course requirement at the University of Miami (Florida) by their participation. Ss signed up and appeared at the laboratory in like-sex pairs. Ss were assigned by sex and in order of appearance across the 36 cells of the design. Although each believed he was participating with a peer, the interaction was with a simulated player. Each $\mathrm{S}$ was seated before an electronic game panel consisting of: the 2 by 2 payoff matrix for the PD, each cell of which could be separately illuminated to indicate S's and simulated player's choices after each trial; two switches for Choice 1 (cooperative) and Choice 2 (competitive) strategy selections; two add-subtract cumulative counters which kept running totals of both S's and simulated player's scores; a series of slots for printed messages, each with a light for incoming and a button for outgoing communications; and a series of lights serving as prompters and guides for the correct sequencing of events during the interaction. The payoff matrix was symmetrical and satisfied the requirements for the $P D$ game (Rapoport \& Chammah, 1965). If both the simulated player and the $S$ cooperated, both gained 4 points; if both competed, both lost 4 points; but if one cooperated while the other competed, then the former lost 5 points while the latter gained 5 .

\section{PROCEDURE}

Each $S$ was seated alone in an experimental cubicle and given a set of printed instructions which were later reviewed orally for the $S$ by the $E$. The rudiments of $P D$ play were explained and Ss were instructed to obtain as many points as they could (an individualistic set). Ss were led to believe that the simulated player could send the posted promise message anytime and could reward the $S$ if the latter did as the message requested. Whenever a white communication light was illuminated on the S's panel, the simulated player transmitted a message which read, "If you make Choice 1 on the next trial, I will add $n$ points to your counter," where $n$ was either 5 or 20 points. Ss were required to communicate their intentions in reply 